\title{
Right ventricular free wall stress after tricuspid valve annuloplasty in acute ovine right heart failure
}

Tomasz Jazwiec, MD, ${ }^{\mathrm{a}, \mathrm{b}}$ Marcin Malinowski, MD, ${ }^{\mathrm{a}, \mathrm{c}}$ Jared Bush, BS, ${ }^{\mathrm{d}}$ Matthew Goehler, BS, Nathan Quay, BS, ${ }^{\mathrm{d}}$ Jessica Parker, MS, ${ }^{\mathrm{d}}$ David E. Langholz, MD, ${ }^{\mathrm{e}}$ and Tomasz A. Timek, MD, PhD ${ }^{\mathrm{a}}$

\section{ABSTRACT}

Background: Tricuspid annuloplasty rings may have a direct impact on right ventricular shape and free wall stress, potentially affecting chamber remodeling and recurrent regurgitation. In an acute model of ovine right heart failure, we investigated right ventricular free wall stress after annuloplasty with different prostheses.

Methods: Thirty-xix sheep underwent implantation of sonomicrometry crystals on the tricuspid annulus and right ventricle. Each group consisted of 9 animals that received a flexible $(28 \pm 1 \mathrm{~mm})$, rigid $(29 \pm 1 \mathrm{~mm})$, or flexible-rigid hybrid $(28 \pm 1 \mathrm{~mm})$ ring. Nine control animals had no ring implanted. Hemodynamic, sonomicrometry, and echocardiographic data were collected before (baselinecontrol group) and during acute right heart failure (control and ring groups). Free wall stress was calculated using the modified Laplace formula for thick shells. Ventricular geometry was determined from 3-dimensional crystal coordinates.

Results: Acute right heart failure reduced right ventricular deformation and fractional volume change while increasing pressure, tricuspid regurgitation grade, cross-sectional area, and free wall stress in control animals versus baseline. All rings significantly decreased right ventricular free wall stress versus control except rigid ring at end-systole. There was no significant difference in free wall stress or tricuspid regurgitation between any ring group during acute heart failure and baseline-control group. No significant difference in free wall stress was observed between any of the ring groups.

Conclusions: Acute right heart failure significantly increased right ventricular free wall stress, which was normalized with equal efficacy by all studied prostheses. Chronic studies are needed to evaluate long-term effects of annuloplasty rings on right ventricle free wall stress and remodeling. (J Thorac Cardiovasc Surg 2019;158:759-68)

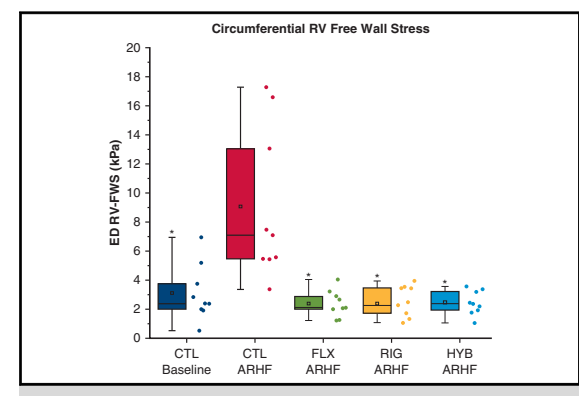

Right ventricle free wall stress after tricuspid annuloplasty in acute right heart failure.

\section{Central Message}

In a sheep model of acute right heart failure tricuspid annuloplasty with different ring prostheses equivalently normalized right ventricular geometry and free wall stress.

\section{Perspective}

Ring annuloplasty for functional tricuspid regurgitation reduces tricuspid insufficiency through annular reduction but may also have a direct effect on right ventricular geometry and shape. The current data provide unique insight into right ventricular free wall stress and geometry after tricuspid annuloplasty with a different ring types in the setting of acute right heart failure.

See Commentary on page 769.
From the ${ }^{\mathrm{a}}$ Division of Cardiothoracic Surgery, ${ }^{\mathrm{d}}$ Research Department, and ${ }^{\mathrm{e}}$ Division of Cardiovascular Medicine, Spectrum Health, Grand Rapids, Mich; ${ }^{\mathrm{b}}$ Department of Cardiac, Vascular and Endovascular Surgery and Transplantology, Medical University of Silesia in Katowice, Silesian Centre for Heart Diseases, Zabrze, Poland; and ${ }^{c}$ Department of Cardiac Surgery, Medical University of Silesia, School of Medicine in Katowice, Katowice, Poland.

Drs Jazwiec and Malinowski are the Peter C. and Pat Cook Endowed Research Fellows in Cardiothoracic Surgery. This study was partially supported by a research grant from Medtronic, Inc.

Read at the 44th Annual Meeting of The Western Thoracic Surgical Association, Goleta, California, June 27-30, 2018.

Received for publication June 18, 2018; revisions received Nov 20, 2018; accepted for publication Nov 26, 2018; available ahead of print Jan 21, 2019.

Address for reprints: Tomasz A. Timek, MD, PhD, Division of Cardiothoracic Surgery, Spectrum Health, Michigan State University College of Human Medicine, 100 Michigan Ave NE, Grand Rapids, MI (E-mail: tomasz.timek@ spectrumhealth.org).

$0022-5223 / \$ 36.00$

Copyright (c) 2018 by The American Association for Thoracic Surgery

https://doi.org/10.1016/j.jtcvs.2018.11.092
Functional tricuspid regurgitation (FTR) is primarily associated with tricuspid annular dilatation and right ventricular (RV) enlargement and dysfunction. ${ }^{1}$ Contemporary repair of FTR is centered on annular reduction and remodeling with prosthetic rings, ${ }^{2,3}$ yet there is no consensus that an annular device is optimal for the maintenance of valvular competency and ventricular geometry. A recent clinical study has shown that tricuspid annuloplasty for FTR may

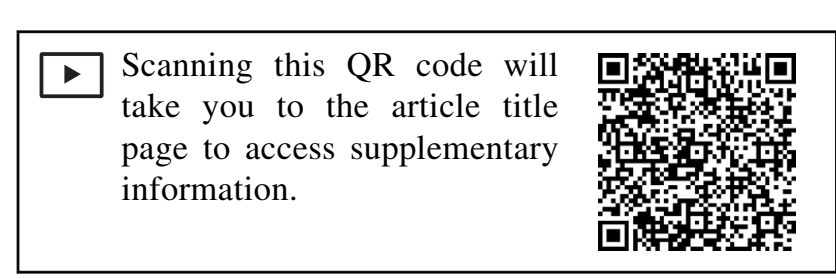




$$
\begin{aligned}
& \text { Abbreviations and Acronyms } \\
& 3 \mathrm{D}=\text { three-dimensional } \\
& \mathrm{ARHF}=\text { acute right heart failure } \\
& \text { CSA }=\text { cross-sectional area } \\
& \mathrm{CTL}=\text { control group } \\
& \mathrm{ECG}=\text { electrocardiogram } \\
& \text { FLX = flexible ring group } \\
& \text { FTR = functional tricuspid regurgitation } \\
& \mathrm{FVC}=\text { fractional volume change } \\
& \text { FWS }=\text { free wall stress } \\
& \text { HYB = flexible-rigid hybrid ring group } \\
& \text { IV = intravenously } \\
& \mathrm{LV}=\text { left ventricle/ventricular } \\
& \text { RIG = rigid ring group } \\
& \mathrm{ROC}=\text { radius of curvature } \\
& \mathrm{RV}=\text { right ventricle/ventricular } \\
& \mathrm{RVP}=\text { right ventricular pressure }
\end{aligned}
$$

have a beneficial effect on RV reverse remodeling. ${ }^{4}$ Similarly, undersized mitral annuloplasty for experimental ischemic mitral regurgitation was previously demonstrated to alter left ventricular (LV) radius of curvature (ROC), ${ }^{5}$ which in turn may decrease LV wall stress. Increased wall stress is one of the initiators of myocardial remodeling and heart failure development ${ }^{6}$ that modifies genetic expression, ${ }^{7}$ coronary blood flow, ${ }^{8}$ and myocardial oxygen consumption. ${ }^{9}$ The $\mathrm{RV}$ is thinner and more compliant then the LV, and it may be expected that annular reduction has a more significant effect on chamber geometry and size of the RV. Tricuspid annuloplasty prostheses may have a variable impact on RV shape, strain, and free wall stress (FWS) and therefore may differentially affect chamber remodeling and recurrent FTR. In an acute model of ovine right heart failure, we set out to investigate RV-FWS after ring annuloplasty with different prostheses.

\section{METHODS}

All animals received humane care in compliance with the Principles of Laboratory Animal Care formulated by the National Society for Medical Research and the Guide for Care and Use of Laboratory Animals prepared by the National Academy of Science and published by the National Institutes of Health. The study was approved by our local Institutional Animal Care and Use Committee.

\section{Operative Procedure}

The operative procedure has been outlined previously. ${ }^{10}$ Thirty-six $(60 \pm 7 \mathrm{~kg})$ healthy Dorset castrated male sheep had external right jugular intravenous catheter placed under local anesthesia with $1 \%$ lidocaine. Animals were then anesthetized with propofol (2-5 mg/kg intravenously [IV]), intubated, and mechanically ventilated. General anesthesia was maintained with inhalational isoflurane (1\%-2.5\%). Fentanyl (5-20 $\mu \mathrm{g} / \mathrm{kg} / \mathrm{min})$ was infused as additional maintenance of anesthesia. A 4-Fr arterial catheter was introduced through the left carotid artery for arterial blood pressure measurements. Animals were fully heparinized, and the right carotid artery and right internal jugular vein were exposed and cannulated in preparation for cardiopulmonary bypass. The operative procedure was performed through a sternotomy, and the heart was exposed in a pericardial cradle.

Pressure transducers (PA4.5-X6; Konigsberg Instruments, Inc, Pasadena, Calif) were placed in the LV and RV through the apex. A 24-mm pulmonary artery pneumatic occluder (In Vivo Metric, Healdsburg, Calif) was placed around the main pulmonary artery. Caval snares were placed around the superior and inferior vena cava. After activated clotting time exceeded 480 seconds, normothermic cardiopulmonary bypass was initiated, both venae cava were snared and the right atrium was opened.

With the heart beating, each animal underwent implantation of 13 ( $2 \mathrm{~mm}$ ) sonomicrometry crystals (Sonometrics Corporation, London, Ontario, Canada) using a 5-0 polypropylene suture (Figure 1). Six crystals were implanted around the tricuspid annulus. One crystal was implanted at each commissure and additional crystal equidistant between the commissures (Video 1). One crystal was sutured on the posterior and septal papillary muscle tips. Four crystals were implanted on the RV myocardium along the mid-RV free wall, with a fifth crystal at the RV apex. After proper implantation of sonomicrometry crystals, each study group consisted of 9 animals that underwent tricuspid valve annuloplasty with flexible Duran AnCore band (FLX), Contour 3-dimensional (3D) rigid band (RIG), or Tri-Ad flexible-rigid hybrid band (HYB) (all Medtronic, Minneapolis, Minn). The remaining 9 animals had no ring implanted and served as controls (CTL).

Following ring implantation, an electrocardiogram (ECG) electrode was sutured to the RV free wall, and a silastic snare was placed around the posterior descending artery branch of the circumflex coronary artery close to the atrioventricular groove. The atriotomy was subsequently closed and the animal was weaned from cardiopulmonary bypass. Every animal received $300 \mathrm{mg}$ of amiodarone IV and was kept on lidocaine IV drip $(0.03 \mathrm{mg} / \mathrm{kg} / \mathrm{min})$ to prevent ventricular ectopy during the experimental protocol. Data collection was performed with the chest open.

All animals were observed for 15 minutes to achieve stable hemodynamics before data collection. Ring groups were studied under acute right heart failure (ARHF) milieu, whereas the CTL group was studied at baseline and during induction of ARHF as presented in Figure 2. At the conclusion of the experiment, the animals were humanely killed by administering sodium pentothal $(100 \mathrm{mg} / \mathrm{kg} \mathrm{IV})$. The heart was excised and proper placement of annular and ventricular crystals was confirmed.

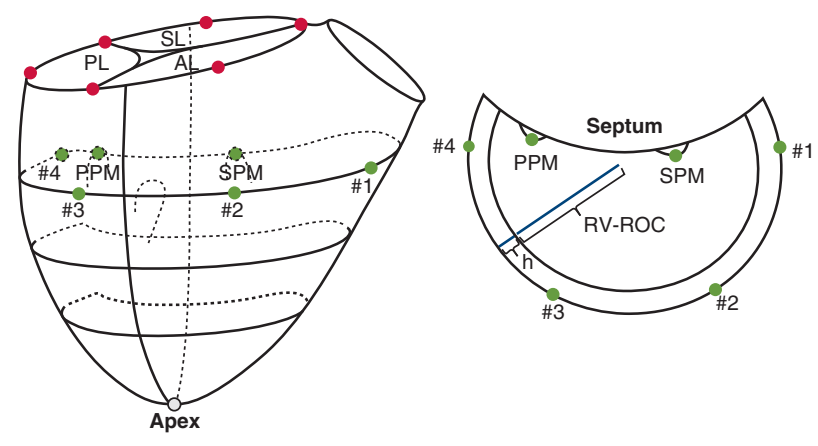

A

B

FIGURE 1. Schematic representation of the sonomicrometry crystal array used in the study. A, Right ventricle with tricuspid valve complex; B, crosssectional view of right ventricle at the level of papillary muscle tips. Numbers 1-4 represents epicardial crystals placed on right ventricular free wall. $P L$, Posterior leaflet; $S L$, septal leaflet; $A L$, anterior leaflet; $P P M$, posterior papillary muscle; $S P M$, septal papillary muscle; $R V$ $R O C$, right ventricle endocardial radius of curvature; $h$, right ventricle free wall thickness. 


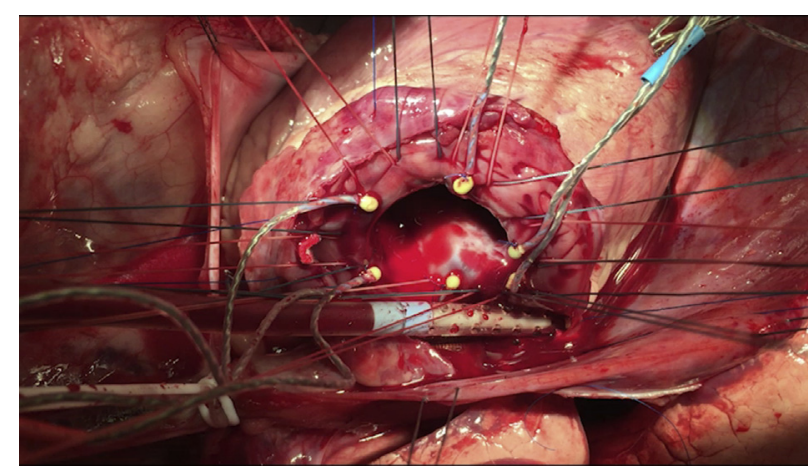

VIDEO 1. Intraoperative view on the ovine tricuspid valve after sonomicrometry crystals placement. Video available at: https://www.jtcvs.org/ article/S0022-5223(18)33224-0/fulltext.

\section{ARHF Model \\ ARHF was induced by combination of 3 separate interventions. Volume load was induced by infusion of $500 \mathrm{~mL}$ of crystalloid solution, whereas myocardial ischemia was achieved with a coronary sling applied around the proximal segment of posterior descending coronary artery. In addition, pulmonary artery constriction with a pneumatic occluder was used to in- crease maximal right ventricular pressure (RVP) to at least $150 \%$ of its pre-occlusion value as described previously. ${ }^{10}$ The animals were permitted to achieve stable hemodynamics for 15 minutes before data collection (Figure 2).}

\section{Sonomicrometry Data Acquisition and Analysis}

All sonomicrometry data were acquired using a Sonometrics Digital U1trasonic Measurement System DS3 (Sonometrics Corporation, London, Ontario, Canada) as previously described. ${ }^{11,12}$ Data from 6 consecutive cardiac cycles during normal sinus rhythm were averaged for each animal. Data were acquired at $128 \mathrm{~Hz}$ with simultaneous LV pressure, RVP, and ECG recordings. All sonomicrometry recordings were analyzed in CardioSOFT Software, ver. 3.4.75 (Sonometrics Corporation).

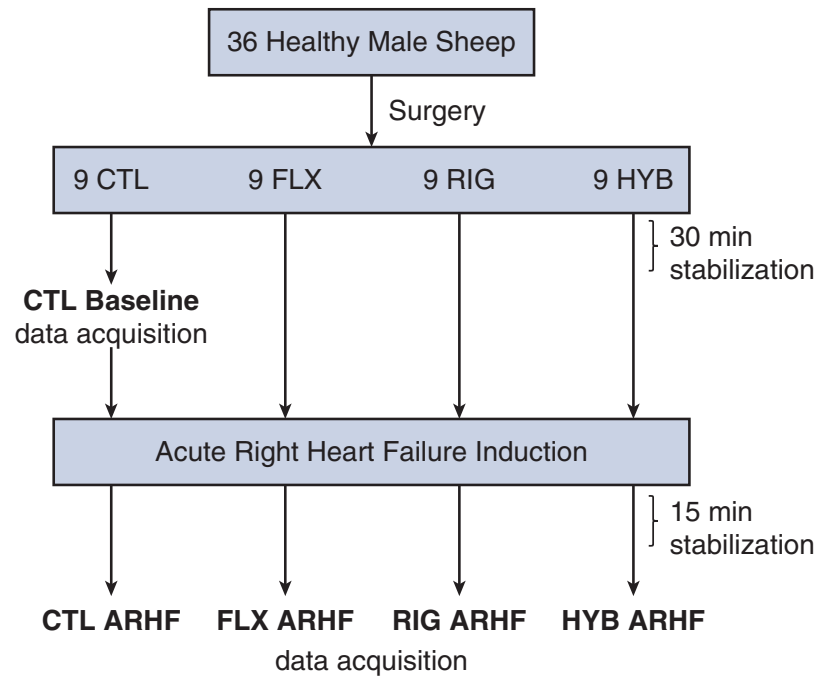

FIGURE 2. Schematic representation of the study protocol. $C T L$, Control group, no ring implanted; $F L X$, flexible ring group (Duran AnCore); $R I G$, rigid $3 \mathrm{D}$ ring group (Contour $3 \mathrm{D}$ ); $H Y B$, hybrid ring group (Tri-AdTM); $A R H F$, acute right heart failure.
All parameters were calculated at end-systole and end-diastole. Enddiastole was defined as the peak of the R-wave on the ECG and endsystole as time of maximum negative $\mathrm{dP} / \mathrm{dt}$ of left ventricular pressure.

Tricuspid annular area, RV cross-sectional area (CSA), and epicardial ROC were calculated from 3D crystal coordinates. RV-CSA was defined as the area circumscribed by crystals marked in green in Figure 1. RVROC was calculated as a difference between radius of epicardial curvature (crystals 1-4) and RV free wall thickness as determined by epicardial echocardiography. RV volume was calculated using convex hull method based on annular and epicardial crystal coordinates. Right ventricular fractional volume change (RV-FVC) was calculated as ( $\left.\mathrm{Vol}_{\mathrm{ED}}-\mathrm{Vol}_{\mathrm{ES}}\right) /$ $\mathrm{Vol}_{\mathrm{ED}} \times 100 \%$, where $\mathrm{Vol}_{\mathrm{ED}}$ is end-diastolic volume and $\mathrm{Vol}_{\mathrm{ES}}$ is endsystolic volume.

\section{Echocardiographic Data Acquisition}

Epicardial echocardiography was used to acquire RV free wall thickness and evaluation of tricuspid valve insufficiency. Images were acquired with a 1.5- to 3.6-Mhz transducer and Vivid S6 ultrasound machine (GE Healthcare, Chicago, Ill). After image acquisition, the end-systolic and end-diastolic RV free wall thickness was measured. Generic length calipers were used to perform the measurements. One caliper was placed at the epicardial layer of the RV free wall and another at the endocardial layer, in the same horizontal plane. All measurements were performed at the equatorial level of the RV and at the same spatial point during systole and diastole, respectively. The degree of valvular insufficiency was assessed using American Society of Echocardiography criteria. The grading included comprehensive evaluation of color flow and continuous-wave Doppler. Tricuspid regurgitation was graded accordingly and categorized by an experienced cardiologist as none or trace $(0)$, mild $(+1)$, moderate $(+2)$, moderate to severe $(+3)$, and severe $(+4)$.

\section{RV Free Wall Stress Analysis}

Circumferential RV-FWS was calculated using the modified Laplace formula for thick shells, described in the following equation ${ }^{13}$ :

$$
\sigma=\frac{\mathrm{P} \times \mathrm{r}}{\mathrm{h} \times\left(2+\frac{\mathrm{h}}{\mathrm{r}}\right)}
$$

Where, $\sigma$ is circumferential RV-FWS, $\mathrm{P}$ is intracavitary pressure, $\mathrm{r}$ is the endocardial ROC, and $\mathrm{h}$ is the wall thickness.

\section{Ventricular Strain Analysis}

The RV free wall circumferential strain was calculated based on the 3D position of crystal 1-4 (Figure 1) using the method previously described. ${ }^{10,14,15}$ Strain is calculated relative to a reference timepoint, and therefore strain in our study reflects the deformation of the RV free wall at end-systole relative to end-diastole.

\section{Statistical Methods}

All data are presented as mean \pm standard deviation or median [interquartile range], depending on test used. Normality was assessed by using Shapiro-Wilk $P$ value in conjunction with skewness and kurtosis values and a histogram. Statistical analysis was performed using one-way analysis of variance if normality and variance assumptions were met. If variance assumption was rejected, a Welch $P$ value was used in place of the analysis of variance $P$ value. Kruskal-Wallis analysis was used if normality assumption wasn't met. To determine what groups showed a statistically significant difference, pairwise comparisons were done using a Bonferroni correction. For the Kruskal-Wallis test, the Wilcoxon rank sum test was used with a Bonferroni correction. All statistical analyses were performed using SAS (SAS Enterprise Guide software, Version 7.1, SAS Institute Inc, Cary, NC). 
TABLE 1. Hemodynamics, right ventricular function, and tricuspid regurgitation grade

\begin{tabular}{|c|c|c|c|c|c|c|}
\hline \multirow[b]{2}{*}{ Group } & \multirow{2}{*}{$\frac{\text { Baseline }}{\text { CTL }(\mathbf{n}=9)^{*}}$} & \multicolumn{4}{|c|}{ Acute right heart failure } & \multirow[b]{2}{*}{$P$ value } \\
\hline & & $\overline{\operatorname{CTL}(n=9)}$ & FLX $(n=9)$ & RIG $(n=9)$ & HYB $(n=9)$ & \\
\hline $\mathrm{LVP}_{\mathrm{MAX}}, \mathrm{mm} \mathrm{Hg}$ & $91.1 \pm 19.3$ & $68.3 \pm 12.9$ & $89.6 \pm 19.3$ & $88.3 \pm 17.1$ & $84.5 \pm 11.6$ & .0198 \\
\hline $\mathrm{RVP}_{\mathrm{MAX}}, \mathrm{mm} \mathrm{Hg}$ & $26.1 \pm 3.8$ & $40.5 \pm 6.4 \dagger$ & $41.1 \pm 8.3 \dagger$ & $39.7 \pm 5.7 \dagger$ & $42.7 \pm 5.6 \dagger$ & .019 \\
\hline $\mathrm{RVP}_{\mathrm{ED}}, \mathrm{mm} \mathrm{Hg}$ & $7.2 \pm 3.3 \ddagger$ & $17.3 \pm 6.9$ & $7.5 \pm 2.6 \ddagger$ & $7.1 \pm 2.6 \ddagger$ & $6.4 \pm 2.4 \ddagger$ & .008 \\
\hline $\mathrm{RVP}_{\mathrm{ES}}, \mathrm{mm} \mathrm{Hg}$ & $22.1 \pm 4.9$ & $30.6 \pm 6.2$ & $29.8 \pm 5.9$ & $29.8 \pm 4.8$ & $29.9 \pm 6.1$ & .014 \\
\hline RV-FVC, $\%$ & $19.6[4.2] \ddagger$ & $12.0[4.0]$ & $18.3[2.1] \ddagger$ & $22.3[11.6]$ & $22.6[10.9] \ddagger$ & .003 \\
\hline TR grade $0-4$ & $0.5[1.0]_{\ddagger}^{\ddagger}$ & $4.0[2.0]$ & $1.0[0.5] \ddagger$ & $0.0[1.0] \ddagger$ & $2.0[1.0]$ & $<.001$ \\
\hline
\end{tabular}

Values are means \pm standard deviation or median [interquartile range]. $C T L$, Control group; $F L X$, flexible ring group; RIG, rigid ring group; $H Y B$, hybrid ring group; $L V P$, left ventricle pressure; $M A X$, maximum; $R V P$, right ventricular pressure; $E D$, end-diastole; $E S$, end-systole; $R V-F V C$, right ventricular fractional volume change; $T R$, tricuspid regurgitation. *The sheep in this group are the same in the CTL acute right heart failure group. $\dagger P<.05$ versus CTL baseline. $\ddagger P<.05$ versus CTL acute right heart failure.

\section{RESULTS \\ Hemodynamics}

Table 1 summarizes hemodynamic and echocardiographic data for CTL at baseline and during ARHF development and after FLX, RIG, and HYB ring implantation during ARHF. CTL animals during ARHF experienced increased RVP and TR grade, which resulted in reduced RV-FVC versus baseline. Implantation of FLX, RIG, and HYB rings in ARHF resulted in normalization of RV-FVC and RVP at end-diastole, whereas end-systolic RVP remained unchanged, as expected. Tricuspid regurgitation grade was significantly decreased by FLX and RIG tricuspid rings versus CTL during ARHF but not by HYB. The mean transvalvular gradients after implantation of FLX, RIG, and HYB were $1.8 \pm 0.9 \mathrm{~mm} \mathrm{Hg}$, $2.1 \pm 1.1 \mathrm{~mm} \mathrm{Hg}$, and $1.8 \pm 0.6 \mathrm{~mm} \mathrm{Hg}$, respectively.

\section{Tricuspid Annular Area and RV Geometry}

Tricuspid annulus area increased in CTL animals during ARHF versus baseline, as shown in Table 2. Implantation of FLX, RIG, and HYB rings in ARHF resulted in significant reduction of annular area in comparison with CTL both at baseline and with ARHF. Tricuspid annulus area reduction was equivalent between all ring groups (Table 2).
RV-CSA after implantation of each ring type was significantly reduced relative to CTL ARHF; however, RV-CSA did not differ between rings or when compared with the baseline CTL group. A similar phenomenon was noted with RV endocardial ROC. RV-ROC was significantly reduced after ring implantation, but no difference was found between ring groups or the baseline CTL conditions (Table 2).

\section{Circumferential RV-FWS}

During ARHF, all rings significantly decreased RVFWS versus CTL at both end diastole and end systole except RIG at end systole. No significant differences in RV-FWS between FLX, RIG, and HYB rings was observed or between all ring groups and CTL baseline (Figure 3).

\section{Circumferential RV Free Wall Strain}

CTL RV free wall strain showed significant reduction of systolic wall deformation with the development of ARHF. This reduction became normalized after implantation of all rings, but there were no differences when RIG ring compared with CTL ARHF (Figure 4).

TABLE 2. Tricuspid annular area and right ventricular geometry

\begin{tabular}{|c|c|c|c|c|c|c|}
\hline \multirow[b]{2}{*}{ Group } & \multirow{2}{*}{$\frac{\text { Baseline }}{\text { CTL }(\mathbf{n}=9)^{*}}$} & \multicolumn{4}{|c|}{ Acute right heart failure } & \multirow[b]{2}{*}{$P$ value } \\
\hline & & $\overline{\operatorname{CTL}(n=9)}$ & FLX $(n=9)$ & RIG $(n=9)$ & HYB $(n=9)$ & \\
\hline $\mathrm{TAA}_{\mathrm{ED}}, \mathrm{cm}^{2}$ & $7.92 \pm 1.77 \dagger$ & $9.97 \pm 1.32$ & $3.50 \pm 0.42 \dagger, \ddagger$ & $3.33 \pm 0.42 \dagger, \ddagger$ & $3.74 \pm 0.83 \dagger, \ddagger$ & $<.001$ \\
\hline $\mathrm{TAA}_{\mathrm{ES}}, \mathrm{cm}^{2}$ & $7.88 \pm 1.87 \dagger$ & $9.90 \pm 1.79$ & $3.44 \pm 0.47 \dagger, \ddagger$ & $3.34 \pm 0.34 \dagger, \ddagger$ & $3.62 \pm 0.77 \dagger, \frac{\dagger}{\dagger}$ & $<.001$ \\
\hline \multicolumn{7}{|l|}{$\mathrm{RV}-\mathrm{CSA}, \mathrm{cm}^{2}$} \\
\hline ED & $24.1 \pm 3.2$ & $27.5 \pm 4$ & $19.5 \pm 2.7 \dagger$ & $21.9 \pm 1.6 \dagger$ & $22.3 \pm 3.7 \dagger$ & $<.001$ \\
\hline ES & $18.4 \pm 3.3$ & $22.9 \pm 4$ & $15.6 \pm 1.8 \dagger$ & $17.2 \pm 2.4 \dagger$ & $16.9 \pm 2.4 \dagger$ & .002 \\
\hline \multicolumn{7}{|l|}{ RV-ROC, mm } \\
\hline ED & $38.7 .0 \pm 2.6$ & $42.0 \pm 2.9$ & $35.3 \pm 3.2 \dagger$ & $35.7 \pm 2.0 \dagger$ & $37.3 \pm 3.4 \dagger$ & $<.001$ \\
\hline ES & $29.1 \pm 2.1 \dagger$ & $33.0 \pm 2.6$ & $25.9 \pm 2.4 \dagger$ & $27.3 \pm 2.0^{\dagger}$ & $26.7 \pm 3.3 \dagger$ & $<.001$ \\
\hline
\end{tabular}

Values are means \pm standard deviation. $C T L$, Control group; $F L X$, flexible ring group; $R I G$, rigid ring group; $H Y B$, hybrid ring group; $T A A$, tricuspid annulus area; $E D$, enddiastole; $E S$, end-systole; $R V$ - $C S A$, right ventricular cross-sectional area; $R V$ - $R O C$, right ventricular endocardial radius of curvature. ${ }^{*}$ The sheep in this group are the same in the CTL acute right heart failure group. $\dagger P<.05$ versus CTL acute right heart failure. $\ddagger P<.05$ versus CTL baseline. 

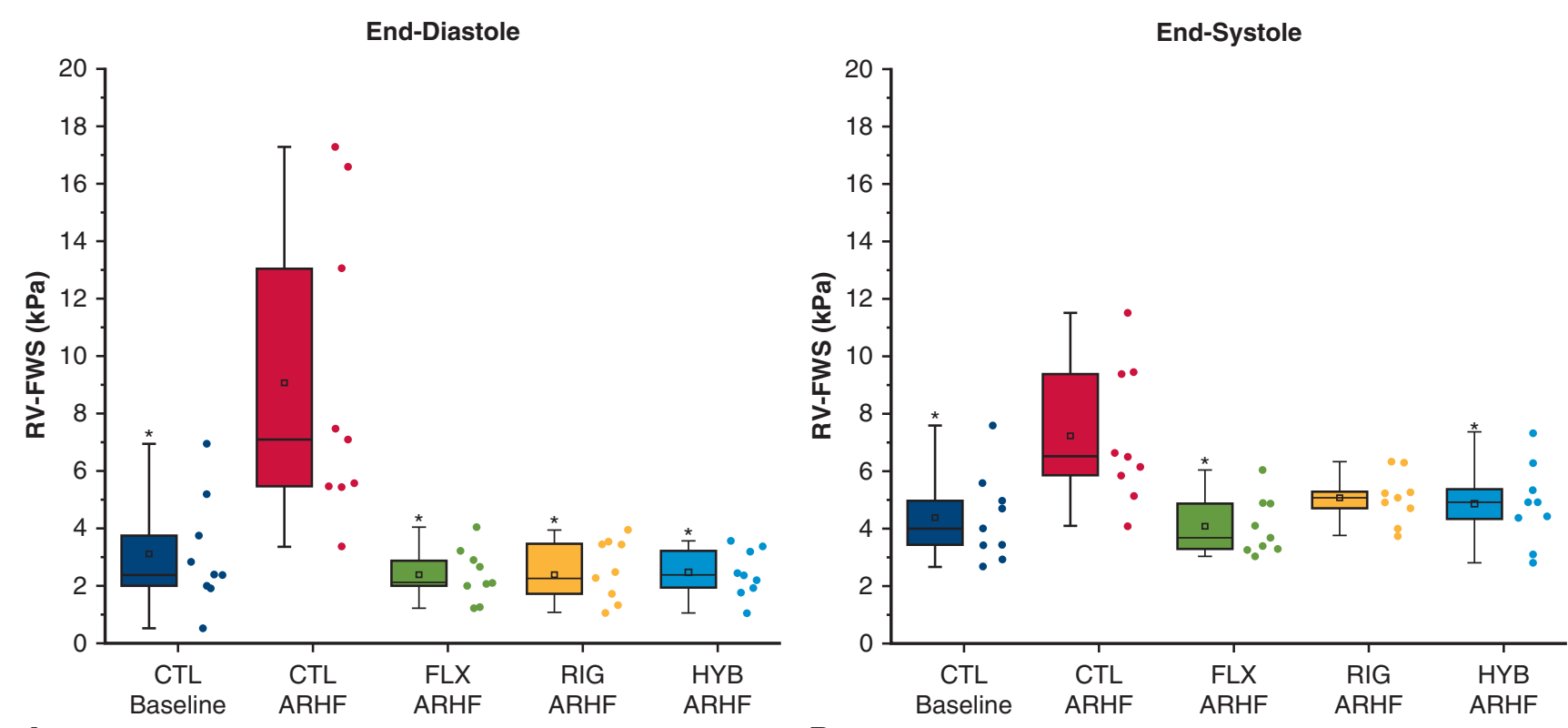

A

B

FIGURE 3. Circumferential right ventricular free wall stress at end diastole (A) and at end systole (B) in the control and study groups. Box indicates range, 25th-75th percentile; horizontal bar, median; square, mean; whiskers, max and min; points, individual data. RV-FWS, Right ventricular free wall stress; $C T L$ Baseline, control group, with no ring implanted during normal condition; $C T L A R H F$, control group, with no ring implanted, during acute right heart failure; $F L X A R H F$, flexible ring group (Duran AnCore) during acute right heart failure; $R I G A R H F$, rigid 3D ring group (Contour 3D) during acute right heart failure; HYB ARHF, hybrid ring group (Tri-AdTM) during acute right heart failure. ${ }^{*} P<.05$ versus CTL ARHF.

\section{DISCUSSION}

Reductive and remodeling ring annuloplasty represent the cornerstone of contemporary surgical repair of FTR, ${ }^{3}$ with demonstrated positive effects on RV geometry ${ }^{4}$ and function. ${ }^{16}$ To investigate the influence of prosthetic annular reduction on RV geometry, we developed an ovine model of ARHF with FTR ${ }^{10}$ encompassing pulmonary hypertension, volume overload, and RV impairment as known clinical determinants of functional tricuspid insufficiency. ${ }^{1,17}$ Furthermore, the presented model includes tricuspid annular area enlargement, thus more realistically reflecting clinical pathophysiology. We found that annular reduction with 3 different prostheses reduced TR grade and RV size and equivalently normalized RV-FWS during ARHF. It is noteworthy that during ARHF, tricuspid regurgitation grade did not differ significantly between CTL and HYB but was significantly reduced with the other ring prostheses. This may be due to the hybrid ring covering less of the circumference of the tricuspid annulus or a differential effect on subvalvular geometry. Clinically, however, this prosthesis has shown good clinical efficacy. ${ }^{18}$

Whether the positive effect of tricuspid annuloplasty on $\mathrm{RV}$ geometry and function is mediated through reduction of volume overload inherent to elimination of tricuspid insufficiency or a direct effect on ventricular geometry remains unclear. Bolling and colleagues ${ }^{19}$ introduced undersized mitral annuloplasty as a surgical treatment option for functional mitral regurgitation suggesting that implantation of a small ring would have a direct remodeling effect on the base of the heart, which in turn may result in decreased wall stress. Experimental studies in sheep subsequently revealed that undersized mitral suture annuloplasty in acute ischemic mitral regurgitation decreased end-systolic regional ROC at the basal, equatorial, and apical levels of LV. ${ }^{5}$ Reduction in ROC would be expected to decrease wall stress as postulated clinically. As the RV is more compliant then the $\mathrm{LV}$, it is not unreasonable to conjecture that annular reduction may have a greater relative influence on ventricular geometry on the right side.

In our study, we observed increased end-diastolic and end-systolic RV-FWS in CTL animals during acute heart failure that became normalized by all studied prostheses except for RIG rings at end-systole. This was most likely related to larger RV free wall ROC seen with RIG at endsystole, yet the underlying mechanism for this finding is difficult to explain, as the annular size was smallest with the rigid ring. RV-CSA and ROC were reduced with ring implantation, suggesting a direct effect of annular reduction on ventricular geometry and shape. Increased end-diastolic ventricular wall stress leads to chamber dilation and shape change, ${ }^{20}$ and $\mathrm{RV}$ dilatation may lead to morphologic changes in the myocardium that promote cardiac failure. ${ }^{21}$ Such adverse remodeling has been reported in patients with functional tricuspid insufficiency and may be halted 


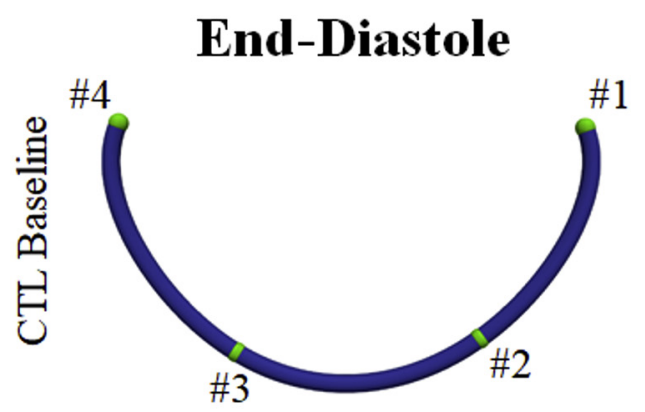

\section{End-Systole}
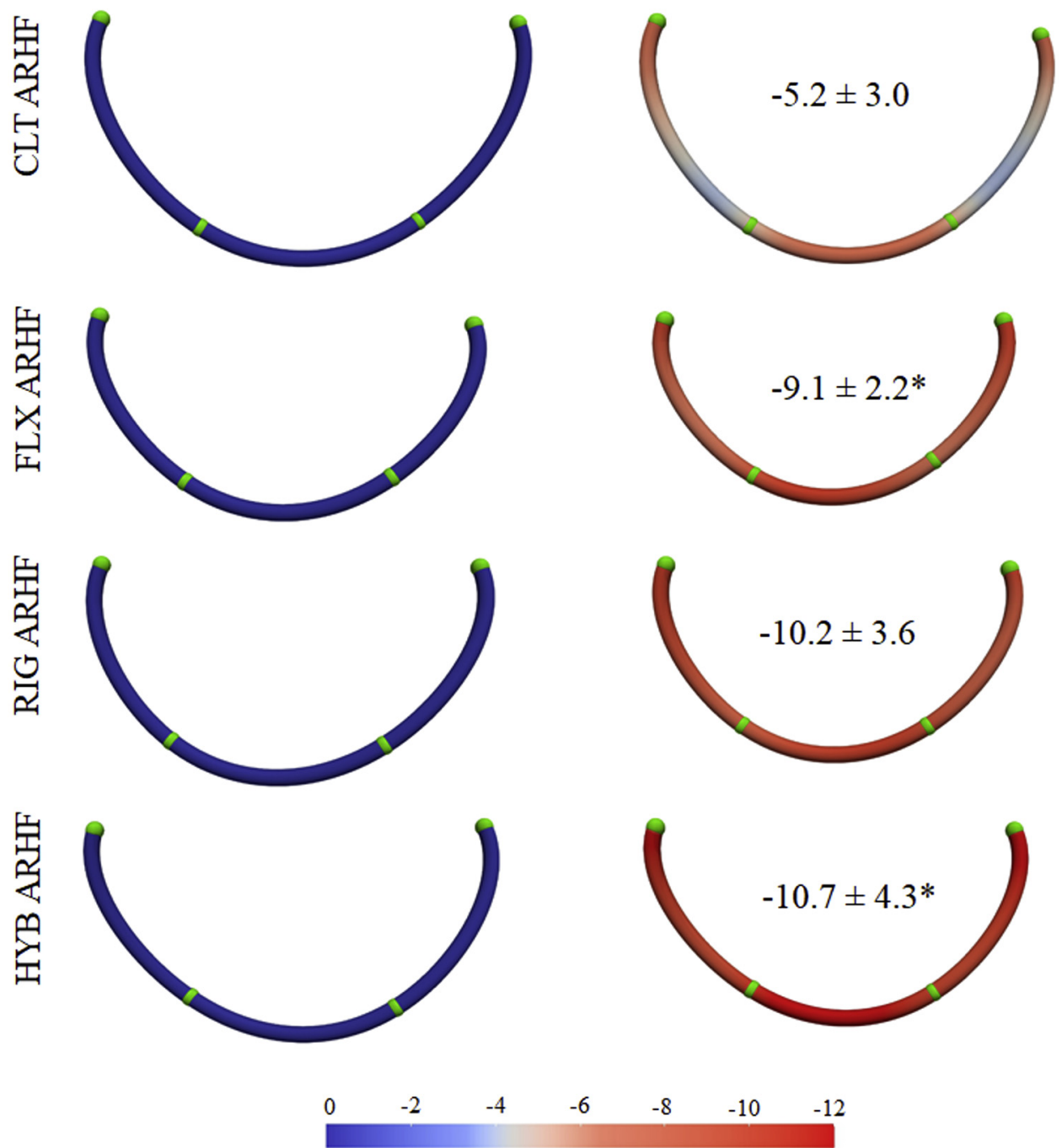

\section{Strain $(\%)$}

FIGURE 4. Illustration of group mean right ventricular cross-sectional shape and color-coded free wall circumferential strain at end systole relative to end diastole; Numbers 1-4 represent epicardial crystals placed on right ventricular free wall; CTL Baseline, Control group, with no ring implanted during normal condition; $C T L A R H F$, control group, with no ring implanted, during acute right heart failure; $F L X A R H F$, flexible ring group (Duran AnCore) during acute right heart failure; $R I G A R H F$, rigid 3D ring group (Contour 3D) during acute right heart failure; HYB ARHF, hybrid ring group (Tri-AdTM) during acute right heart failure. $* P<.05$ versus CTL ARHF.

with prosthetic annular reduction. ${ }^{4}$ Our data corroborate these clinical findings, as annular reduction may not only diminish TR but also directly decrease chamber size and wall stress in a dysfunctional RV.
Decrease of wall stress by reductive tricuspid annuloplasty may decrease oxygen consumption and normalize delivery of blood to the RV myocardium, thus optimizing energetics. $\mathrm{RV}$ and LV coronary perfusion profiles differ significantly as 


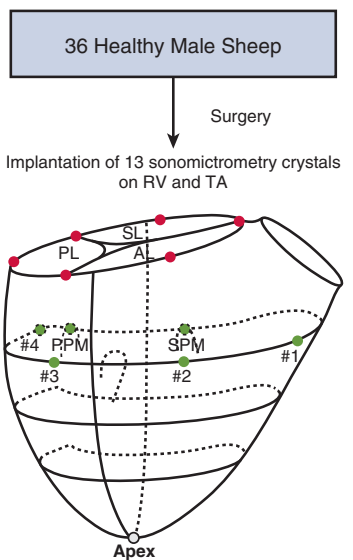

Tricuspid annuloplasty ring implantation and acute right heart failure developement

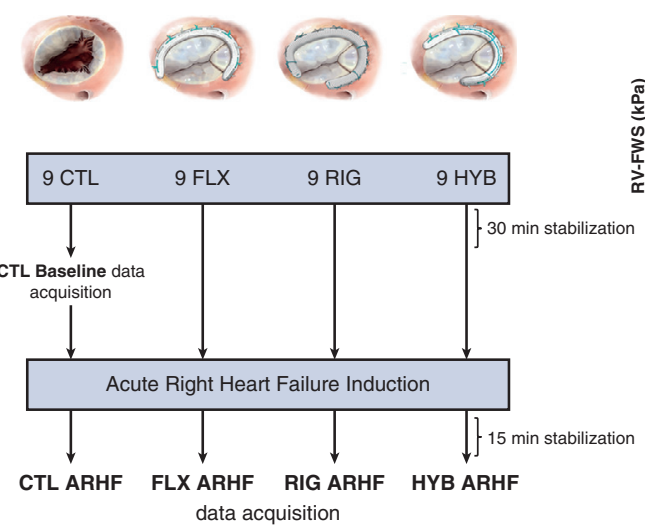

Circumferential right ventricular free wall stress End-Diastole

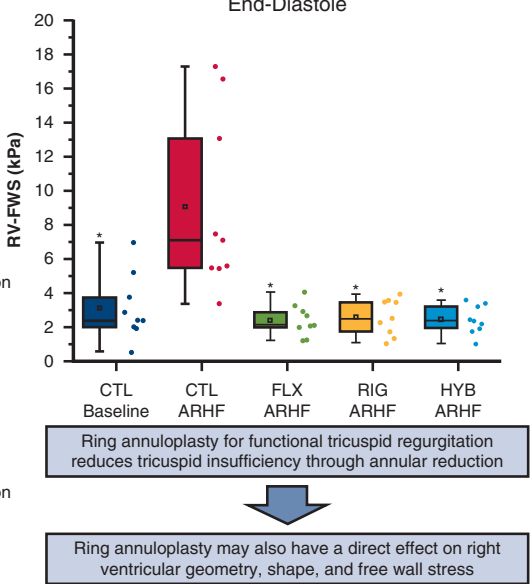

FIGURE 5. The graphical depiction of the methods, results, and implications of the present study. $R V$, Right ventricle; $T A$, tricuspid annulus; $P L$, posterior leaflet; $S L$, septal leaflet; $A L$, anterior leaflet; $P P M$, posterior papillary muscle; $S P M$, septal papillary muscle; $C T L$, control group, no ring implanted; $F L X$, flexible ring group (Duran AnCore); RIG, rigid 3D ring group (Contour 3D); HYB, hybrid ring group (Tri-AdTM); CTL Baseline, control group, with no ring implanted during normal condition; $C T L A R H F$, control group, with no ring implanted, during acute right heart failure; $F L X A R H F$, flexible ring group (Duran AnCore) during acute right heart failure; $R I G A R H F$, rigid 3D ring group (Contour 3D) during acute right heart failure; $H Y B$ ARHF, hybrid ring group (Tri-AdTM) during acute right heart failure; $R V$-FWS, right ventricular free wall stress. Whiskers, box plot; box, range 25 th- 75 th percentile; horizontal bar, median; square, mean; whiskers, max and min; points, individual data.

right-side coronary blood flow is lower during the heart cycle and perfusion of the right heart is maintained during both systole and diastole. ${ }^{22}$ Coronary blood flow deteriorates with increased wall stress, ${ }^{8}$ whereas myocardium oxygen requirements to maintain performance increase, ${ }^{9}$ impacting the ventricle under greater hemodynamic load. Reduction of chamber size and wall stress associated with tricuspid ring annuloplasty observed in our study would be expected to reduce myocardial work and oxygen needs. It is therefore plausible that the combination of reduced volume overload and improved ventricular energetics induced by prosthetic annular reduction provides the optimal milieu for reverse RV remodeling observed clinically.

Annular size reduction by ring or suture annuloplasty represents the basic concept of FTR repair, but selection of proper ring size is still controversial ${ }^{23-25}$ yet may be crucial to achieve optimal clinical outcomes. ${ }^{26-28}$ Aggressive same dimension undersized annuloplasty for simultaneous functional tricuspid and mitral valve repair has been shown to provide good control of tricuspid insufficiency without causing tricuspid stenosis. ${ }^{26}$ Although the efficacy of De Vega annuloplasty for FTR has been questioned, ${ }^{23,29,30}$ a recent study has demonstrated that when well standardized and "tightly" reductive, suture annuloplasty provides equivalent results to a flexible ring prosthesis. ${ }^{27}$ It is reasonable to assume that if reduction of the tricuspid annulus is greater the impact on the right ventricle geometry more evident and the decrease in wall stress more pronounced. As such, it may not be the annuloplasty type but the degree of annular reduction that is central to prevention of right ventricular remodeling and recurrent TR. In our study, the size of the tricuspid ring was selected in accordance to manufacturers' guidelines. Both intercommissural distance of septal leaflet and anterior leaflet area were measured to choose the appropriate ring dimension. However, sizing was based on healthy normal sheep hearts and resulted in reduction of tricuspid annular area by $58 \%$, $56 \%$, and $53 \%$ in RIG, FLX, and HYB rings, respectively. In the clinical setting of FTR and annular dilation, this reduction may be more pronounced.

Aggressive annular reduction has been demonstrated to reduce myocardial performance of the basal segments of the $\mathrm{LV}^{31}$ and similar mechanisms may be at work on the right side. In our study, RV circumferential strain significantly increased and RV-FVC decreased with induction of ARHF and returned to normal after ring prosthesis implantation. There were no statistical differences in RV free wall strain with RIG ring compared with CTL ARHF at end systole in our experiment. We postulate that aggressive annular reduction, as was seen with the rigid ring, may have a significant influence on regional myocardial function as previously demonstrated with undersized mitral annular prostheses, ${ }^{31}$ resulting in lack of improved free wall strain. However, normalization of RV strain with FLX and HYB rings suggests lack of a deleterious effect of annular reduction on free wall regional function. We did not specifically investigate regional function in the basal segments of the RV, and previous studies in ovines have demonstrated that mitral annular reduction reduces basal but not equatorial myocardial 
segment function. ${ }^{32}$ The influence of tricuspid annuloplasty size on the balance between optimal RV-FWS and regional myocardial function requires further study.

The current study demonstrated that during acute ovine right heart failure tricuspid ring annuloplasty not only significantly decreased annular area and valvular insufficiency but also had an important influence on acute reverse remodeling by decreasing RV size. The studied ring prostheses normalized RV-FWS stress and strain and FVC during acute right heart dysfunction (Figure 5). These data suggest that reductive tricuspid annuloplasty may in part offer a solution to the "ventricular problem" of FTR. As more aggressive approach toward tricuspid valve repair is advocated by current guidelines with repair being recommended based on annular size even in the absence of significant insufficiency, the concept of a "prophylactic" or "preventive" tricuspid annuloplasty is gaining clinical acceptance and is supported by our data.

\section{Limitations}

The results of our study must be interpreted in the context of important limitations. This was an acute open-chest experiment with inherent effects of anesthesia and an open thorax on RV dynamics. ${ }^{11,33}$ To calculate RV circumferential wall stress, the Modified Laplace law was applied. This law is based on a global force balance, ignores myocardial material properties, and refers only to the average stress across the entire wall thickness. Therefore, it cannot be used to calculate stress in the local muscle fiber or cross fiber direction. Nonetheless, circumferential LV wall stress calculated by the modified Laplace law has been validated with finite element analysis at end-systole although it may be slightly overestimated at end-diastole. ${ }^{13}$ We did not study the mechanics of the ventricular septum after implantation of tricuspid annuloplasty prostheses during ARHF and its potential influence on RV free wall geometry; however, our previous study ${ }^{10}$ revealed that during isolated posterior descending coronary artery ischemia ventricular interdependence is a factor that affects RV function and may contribute to tricuspid regurgitation. Implantation of tricuspid annuloplasty prosthesis before induction of ARHF does not reflect the clinical scenario. Therefore, the effect of ring annuloplasty was rather to prevent increased wall stress during ARHF than correct it. Only healthy animals were included in the experiment, and, as such, great caution needs to be exercised in extrapolating these results clinically. Nonetheless, direct effect of ring annuloplasty on RV geometry and energetics is a significant finding that we anticipate should also be seen with clinical chronic FTR and RV dilation as it represents a mechanical effect. Chronic studies of RV failure and FTR are needed to evaluate long-term effects of annular prostheses on RV free-wall stress, remodeling, and valvular insufficiency.

\section{Conflict of Interest Statement}

Authors have nothing to disclose with regard to commercial support.

The authors gratefully acknowledge the superb echocardiographic assistance provided by Rachel Phillion and Lou Mitchell.

\section{References}

1. Dreyfus GD, Martin RP, Chan KM, Dulguerov F, Alexandrescu C. Functional tricuspid regurgitation: a need to revise our understanding. J Am Coll Cardiol. 2015;65:2331-6.

2. Falk V, Baumgartner H, Bax JJ, De Bonis M, Hamm C, Holm PJ, et al. 2017 ESC/ EACTS guidelines for the management of valvular heart disease. Eur J Cardiothorac Surg. 2017;52:616-64.

3. Nishimura RA, Otto CM, Bonow RO, Carabello BA, Erwin JP, Guyton RA, et al. 2014 AHA/ACC guideline for the management of patients with valvular heart disease: executive summary. A report of the American College of Cardiology/ American Heart Association task force on practice guidelines. J Thorac Cardiovasc Surg. 2014;148:e1-132.

4. Sakata T, Mogi K, Sakurai M, Nomura A, Fujii M, Kaneyuki D, et al. Effect of tricuspid annuloplasty concomitant with left heart surgery on right heart geometry and function. J Thorac Cardiovasc Surg. 2018;156:1050-61.

5. Tibayan FA, Rodriguez F, Langer F, Liang D, Daughters GT, Ingels NB, et al. Undersized mitral annuloplasty alters left ventricular shape during acute ischemic mitral regurgitation. Circulation. 2004;110:Ii98-102.

6. Grossman W. Cardiac hypertrophy: useful adaptation or pathologic process? Am J Med. 1980;69:576-84.

7. Chien KR. Stress pathways and heart failure. Cell. 1999;98:555-8.

8. Jan KM. Distribution of myocardial stress and its influence on coronary blood flow. J Biomech. 1985;18:815-20.

9. Strauer BE, Beer K, Heitlinger K, Hofling B. Left ventricular systolic wall stress as a primary determinant of myocardial oxygen consumption: comparative studies in patients with normal left ventricular function, with pressure and volume overload and with coronary heart disease. Basic Res Cardiol. 1977;72: 306-13.

10. Malinowski M, Proudfoot AG, Eberhart L, Schubert H, Wodarek J, Langholz D, et al. Large animal model of acute right ventricular failure with functional tricuspid regurgitation. Int J Cardiol. 2018;264:124-9.

11. Jazwiec T, Malinowski M, Proudfoot AG, Eberhart L, Langholz D, Schubert H, et al. Tricuspid valvular dynamics and 3-dimensional geometry in awake and anesthetized sheep. J Thorac Cardiovasc Surg. 2018;156:1503-11.

12. Malinowski M, Wilton P, Khaghani A, Langholz D, Hooker V, Eberhart L, et al. The effect of pulmonary hypertension on ovine tricuspid annular dynamics. Eur J Cardiothorac Surg. 2016;49:40-5.

13. Zhang Z, Tendulkar A, Sun K, Saloner DA, Wallace AW, Ge L, et al. Comparison of the Young-Laplace law and finite element based calculation of ventricular wall stress: implications for postinfarct and surgical ventricular remodeling. Ann Thorac Surg. 2011;91:150-6.

14. Rausch MK, Bothe W, Kvitting JP, Swanson JC, Ingels NB Jr, Miller DC, et al. Characterization of mitral valve annular dynamics in the beating heart. Ann Biomed Eng. 2011;39:1690-702.

15. Rausch MK, Malinowski M, Wilton P, Khaghani A, Timek TA. Engineering analysis of tricuspid annular dynamics in the beating ovine heart. Ann Biomed Eng. 2018;46:443-51.

16. Chikwe J, Itagaki S, Anyanwu A, Adams DH. Impact of concomitant tricuspid annuloplasty on tricuspid regurgitation, right ventricular function, and pulmonary artery hypertension after repair of mitral valve prolapse. J Am Coll Cardiol. 2015;65:1931-8.

17. Tei C, Pilgrim JP, Shah PM, Ormiston JA, Wong M. The tricuspid valve annulus: study of size and motion in normal subjects and in patients with tricuspid regurgitation. Circulation. 1982;66:665-71.

18. Milla F, Castillo JG, Varghese R, Chikwe J, Anyanwu AC, Adams DH. Rationale and initial experience with the Tri-Ad Adams tricuspid annuloplasty ring. J Thorac Cardiovasc Surg. 2012;143:S71-3.

19. Bolling SF, Pagani FD, Deeb GM, Bach DS. Intermediate-term outcome of mitral reconstruction in cardiomyopathy. J Thorac Cardiovasc Surg. 1998;115:381-6; discussion 387-8.

20. Ross J Jr. Adaptations of the left ventricle to chronic volume overload. Circ Res. 1974;35(suppl II):64-70. 
21. Agger P, Ilkjaer C, Laustsen C, Smerup M, Frandsen JR, Ringgard S, et al. Changes in overall ventricular myocardial architecture in the setting of a porcine animal model of right ventricular dilation. J Cardiovasc Magn Res. 2017;19:93.

22. Hess DS, Bache RJ. Transmural right ventricular myocardial blood flow during systole in the awake dog. Circ Res. 1979;45:88-94.

23. McCarthy PM, Bhudia SK, Rajeswaran J, Hoercher KJ, Lytle BW, Cosgrove DM, et al. Tricuspid valve repair: durability and risk factors for failure. J Thorac Cardiovasc Surg. 2004;127:674-85.

24. Navia JL, Nowicki ER, Blackstone EH, Brozzi NA, Nento DE, Atik FA, et al. Surgical management of secondary tricuspid valve regurgitation: annulus, commissure, or leaflet procedure? J Thorac Cardiovasc Surg. 2010;139:1473-82.e1475.

25. Antoniali F, Braile DM, Poterio GM, Ribeiro GC, Costa CE, Lopes MM. Tricuspid valve repair using the proportion between segments of normal tricuspid annulus as a parameter for annuloplasty. Rev Bras Cir Cardiovasc. 2007;22:393-9.

26. Huffman LC, Nelson JS, Lehman AN, Krajacic MC, Bolling SF. Identical tricuspid ring sizing in simultaneous functional tricuspid and mitral valve repair: a simple and effective strategy. J Thorac Cardiovasc Surg. 2014;147:611-4.

27. Shinn SH, Dayan V, Schaff HV, Dearani JA, Joyce LD, Lahr B, et al. Outcomes of ring versus suture annuloplasty for tricuspid valve repair in patients undergoing mitral valve surgery. J Thorac Cardiovasc Surg. 2016;152:406-15.e403.

28. Rogers JH, Bolling SF. Valve repair for functional tricuspid valve regurgitation: anatomical and surgical considerations. Semin Thorac Cardiovasc Surg. 2010; 22:84-9.

29. Tang GH, David TE, Singh SK, Maganti MD, Armstrong S, Borger MA. Tricuspid valve repair with an annuloplasty ring results in improved long-term outcomes. Circulation. 2006;114:I577-81.

30. Rivera R, Duran E, Ajuria M. Carpentier's flexible ring versus De Vega's annuloplasty. A prospective randomized study. J Thorac Cardiovasc Surg. 1985;89: 196-203.

31. Cheng A, Nguyen TC, Malinowski M, Liang D, Daughters GT, Ingels NB Jr, et al. Effects of undersized mitral annuloplasty on regional transmural left ventricular wall strains and wall thickening mechanisms. Circulation. 2006;114:I600-9.

32. Cheng A, Nguyen TC, Malinowski M, Liang D, Daughters GT, Ingels NB Jr, et al. Undersized mitral annuloplasty inhibits left ventricular basal wall thickening but does not affect equatorial wall cardiac strains. J Heart Valve Dis. 2007; 16:349-58.

33. Priebe HJ. Differential effects of isoflurane on regional right and left ventricular performances, and on coronary, systemic, and pulmonary hemodynamics in the dog. Anesthesiology. 1987;66:262-72.

Key Words: tricuspid valve, valve repair, functional tricuspid regurgitation, right ventricular stress, right ventricular geometry

\section{Discussion}

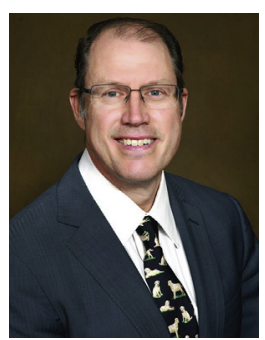

Dr Joseph Cleveland. Okay, paper number six is "Right Ventricular Free Wall Stress After Tricuspid Valve Annuloplasty in Acute Ovine Right Heart Failure," to be presented by Tomasz Jazwiec. Did I get that right? Okay, from Spectrum Health in Grand Rapids, Michigan.

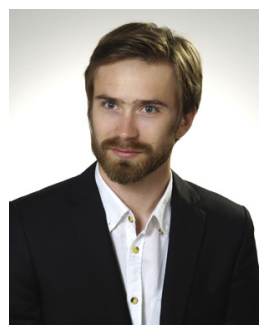

Dr Tomasz Jazwiec (Grand Rapids, Mich). Good morning. We would like to thank the Association for the opportunity to present our study investigating "Right Ventricular Free Wall Stress After Tricuspid Valve Annuloplasty in Acute Ovine Right Heart Failure." This study was partially funded by a grant from Medtronic Corporation.
Tricuspid annuloplasty processes may have a variable impact on RV shape and free wall stress and therefore differentially affecting chamber remodeling and recurrent FTR. In an acute ovine model of right heart failure, we set out to investigate RV free wall stress after ring annuloplasty with different prostheses. As presented in the upper feature to the right in the experiment, 36 animals underwent implantation of 13 sonomicrometric crystals while on cardiopulmonary bypass and with the heart beating. Subsequently, animals were divided into 4 groups that underwent tricuspid annuloplasty with either anchored flexible ring, triad flexible rigid hybrid ring, contour rigid ring, or had no ring implanted and served as controls. Animals were studied after weaning from cardiopulmonary bypass and after hemodynamic stabilization. Acute right heart failure was induced by combination of volume infusion, snare occlusion of posterior distending coronary artery, and pneumatic occlusion of pulmonary artery to increase RV pressure 50\% above baseline. Simultaneous hemodynamic and hemodynamic echocardiographic and sonomicrometry data were collected before and after induction of ARHF as presented in the experimental protocol in the lower feature to the right. Circumferential RV free wall stress was calculated from 3D crystal coordinates and echocardiographically determined RV wall thickness using modified Laplace formula for thick shells.

Let's now look at the results. As presented in the upper table summarizing hemodynamic parameters, ARHF in acute, in control animals, decreased RV fractional volume change while increasing RV pressure and tricuspid regurgitation rate. In the lower table, we can observe that implantation of any of the annuloplasty prosthesis was associated with reduced RV-CSA and reduced curvature versus control animals during ARHF, which suggested direct effect of reductive annuloplasty on the RV chamber. Calculated circumferential RV-FWS is presented in the feature to the right. ARHF significantly increased RV wall stress in control animals at both end-systole and diastole, which was decreased by all standard prostheses except rigid at endsystole; however, there was no significant difference in RV-FWS between flexible, rigid, and hybrid rings or all rings and control baseline group.

In conclusion, ARHF in normal-shaped hearts significantly increased RV-FWS, which was normalized with equal efficiency by all studied annuloplasty prostheses. Nonetheless, chronic studies are needed to evaluate long-term effect of annular prosthesis on RV-FWS and remodeling.

Thank you very much.

Dr Cleveland. That's a very nice study and I think acutely you show us that you can affect the geometry of the RV. I guess I'm just sitting here thinking, would I ever put an acute or a ring in acutely failing RV and I guess that's one question, is that what you would take away from 
these data and, and I would certainly agree, I think, I guess the chronic situations were, you know, typically you see tricuspid regurgitation over long-term and the RV remodels, and that's really the kind of where things are interesting.

Dr Jazwiec. Yeah, that's true. Of course, this is an acute study, and all the results should be taken with caution when translating to the clinic studies and practice.
Speaker. Can you turn this into a product model for right heart failure?

Dr Jazwiec. I think so because actually in our laboratory now we are working on tachycardia-induced RV and LV failure and this is what we are going to do next.

Speaker. Thank you.

Dr Jazwiec. Thank you.

Dr Cleveland. Thank you. 